\title{
Gastric Adenoma
}

National Cancer Institute

\section{Source}

National Cancer Institute. Gastric Adenoma. NCI Thesaurus. Code C7699.

A neoplastic polyp that arises from the stomach. This category includes intestinal-type adenomatous polyps, gastric-type adenomas, and fundic gland polyps. 